\title{
Change in platelet endothelial cell adhesion molecule-1 immunoreactivity in the dentate gyrus in gerbils fed a folate-deficient diet
}

\author{
Ki-Yeon Yoo - In Koo Hwang · Young Sup Kim • \\ Dae Young Kwon $\cdot$ Moo Ho Won
}

Published online: 16 November 2007

(C) Springer-Verlag 2007

\begin{abstract}
Folate deficiency increases stroke risk. We examined whether folate deficiency affects platelet endothelial cell adhesion molecule-1 (PECAM-1), which is an immunoglobulin-associated cell adhesion molecule and mediates the final common pathway of neutrophil transendothelial migration, in blood vessels in the gerbil dentate gyrus after transient forebrain ischemia. Gerbils were exposed to a folic acid-deficient diet (FAD) for 3 months and then subjected to common carotid artery occlusion for 5 min. In the control diet (CD)- and FAD-treated shamoperated groups, weak PECAM-1 immunoreactivity was detected in the blood vessels located in the dentate gyrus. PECAM-1 immunoreactivity in both groups was increased by 4 days after ischemic insult. PECAM-1 immunoreactivity in the FAD-treated group was twice as high that in the CD-treated-sham-operated group 4 days after ischemic insult. Western blot analyses showed that the change
\end{abstract}

K.-Y. Yoo · M. H. Won $(\bowtie)$

Department of Anatomy and Neurobiology,

College of Medicine, Hallym University,

Chuncheon 200-702, Republic of Korea

e-mail: mhwon@hallym.ac.kr

\section{K. Hwang}

Department of Anatomy and Cell Biology,

College of Veterinary Medicine and BK21 Program

for Veterinary Science, Seoul National University,

Seoul 151-742, Republic of Korea

Y. S. Kim

Korea Research Institute of Chemical Technology,

Taejeon 305-343, Republic of Korea

D. Y. Kwon

Division of Functional Food Research,

Korea Food Research Institute, Songnam,

Kyoungki-do 463-746, Republic of Korea patterns in PECAM-1 protein levels in the dentate gyrus in both groups after ischemic insult were similar to changes in PECAM-1 immunohistochemistry in the ischemic dentate gyrus. Our results suggest that folate deficiency enhances PECAM-1 in the dentate gyrus induced by transient ischemia.

Keywords Dentate gyrus - Gerbil - Hippocampus ·

Microvessels · Neuronal damage .

Platelet endothelial cell adhesion molecule-1 .

Transient forebrain ischemia

\section{Introduction}

The blood-brain barrier (BBB) is a physiological barrier between the blood and the central nervous system (CNS) and is composed of brain parenchymal microvascular endothelial cells, astrocyte foot processes and pericytes. The BBB exhibits a low and strictly controlled permeability to blood-borne compounds, mainly due to the presence of interendothelial tight junctions [18].

When the brain has inflammatory situations, massive infiltration of leukocytes is observed in the brain tissue, together with the expression of various adhesion molecules such as selectins and immunoglobulin superfamily on the surface of cerebral vascular endothelium [6]. Inflammation is a hallmark of various CNS diseases such as bacterial and viral infections, multiple sclerosis, trauma, Alzheimer's disease, and cerebral ischemia [2, 25].

Transient forebrain ischemia produced by the temporary deprivation of blood flow to the brain causes the insidious delayed degeneration of specific vulnerable neurons in the hippocampus, neocortex and striatum [22]. The neuronal death is caused by depolarization-induced calcium entry 
via $N$-methyl-D-aspartate receptors $[3,30]$, by intracellular free radical generation $[1,5,35]$ or by cell death pathway [24].

The expansion of infarction after ischemia is due to microcirculatory disturbance [9] and selective neuronal vulnerability [13]. The microcirculatory disturbance may be induced by forming capillary block, BBB damage, vasoconstriction, biochemical mediators such as reactive oxygen species (ROS), leukotrienes, cytokines, plateletactivating factor, and proteolytic enzymes stemming from interaction between leukocytes and perturbed endothelium in the ischemic region [9, 33].

Platelet endothelial cell adhesion molecule-1 (PECAM$1, \mathrm{CD}-31)$ is a member of the immunoglobulin-associated cell adhesion molecule family and present on neutrophils and endothelial cells, and which mediates the final common pathway of neutrophil transendothelial migration [28].

Up to now, no studies reported the ischemia-related changes of PECAM-1 expression in the dentate gyrus after transient forebrain ischemia in the Mogolian gerbil. Therefore, in the present study, we examined the chronological alteration of PECAM-1 immunoreactivity in the dentate gyrus after $5 \mathrm{~min}$ of transient forebrain ischemia using a gerbil ischemia model.

\section{Materials and methods}

Experimental animals, diets and measurements of homocysteine level

The progeny of male Mongolian gerbils (Meriones unguiculatus) were obtained from the Experimental Animal Center, Hallym University, Chuncheon, South Korea.

Mongolian gerbils were used at 3 months of age (body weight, $35 \pm 0.5 \mathrm{~g}$ ). The animals were housed in a conventional state under adequate temperature $\left(23^{\circ} \mathrm{C}\right)$ and humidity $(60 \%)$ control with a $12: 12 \mathrm{~h}$ light:dark cycle, and exposed to a control versus experimental diet for 3 months. The control diet (CD) was a standard mouse diet, which contained defined choline and folate (Altromin control diet C1000 or AIN93), whereas the experimental diet, folic deficient diet (FAD, $<0.5 \mathrm{mg} / \mathrm{kg}$; Altromin, special diet C1027). Both chows were supplemented with $1 \%$ succinylsulfathiazole (Sigma-Aldrich, Miss., USA) for selective intestinal decontamination. The animals were fed with the respective diet ad libitum for 3 months. All of the experiments were conducted to minimize the number of animals involved and the suffering caused by the procedures used in the present study.

After 3 months on the diets, blood was taken for analysis of homocysteine levels. Homocysteine levels in serum samples were quantified with the use of an IMx immunoassay analyzer (Abbott Laboratories) according to the protocol provided by the manufacturer.

Induction of transient forebrain ischemia

The animals were anesthetized with a mixture of $2.5 \%$ isoflurane in $33 \%$ oxygen and $67 \%$ nitrous oxide. Bilateral common carotid arteries were isolated and occluded using non-traumatic aneurysm clips. The complete interruption of blood flow was confirmed by observing the central artery in retinae using an ophthalmoscope. After 5 min of occlusion, the aneurysm clips were removed from the common carotid arteries. The body (rectal) temperature under free-regulating or normothermic $\left(37 \pm 0.5^{\circ} \mathrm{C}\right)$ conditions was monitored with a rectal temperature probe (TR100; YSI, USA) and maintained using a thermometric blanket before, during and after the surgery until the animals completely recovered from anesthesia. Thereafter, animals were kept on the thermal incubator (Mirae Medical Industry, South Korea) to maintain the body temperature of animals until the animals were euthanized. Sham-operated animals were subjected to the same surgical procedures except that the common carotid arteries were not occluded $[14,16]$.

\section{Immunohistochemistry}

Sham-operated and ischemia-operated animals ( $n=7$ at each time point) at designated times (1, 2 and 4 days after the surgery) were sacrificed. The animals were anesthetized with sodium pentobarbital and perfused transcardially with $0.1 \mathrm{M}$ phosphate-buffered saline (PBS, pH 7.4) followed by $4 \%$ paraformaldehyde in $0.1 \mathrm{M}$ phosphate-buffer (PB, $\mathrm{pH}$ 7.4). The brains were removed and post-fixed in the same fixative for $6 \mathrm{~h}$. The brain tissues were cryoprotected by infiltration with $30 \%$ sucrose overnight. Thereafter, frozen tissues were serially sectioned on a cryostat (Leica, Germany) into 30- $\mu \mathrm{m}$ coronal sections, and they were then collected into six-well plates containing PBS.

To obtain the exact data of immunohistochemistry, the free-floating sections were simultaneously processed by immunohistochemistry under the same condition. The animals were anesthetized with pentobarbital sodium, and perfused transcardially with $0.1 \mathrm{M}$ phosphate-buffered saline (PBS, pH 7.4) followed by $4 \%$ paraformaldehyde in $0.1 \mathrm{M} \mathrm{PB}(\mathrm{pH} 7.4)$ at the designated times after the surgery. Brains were removed, and postfixed in the same fixative for $6 \mathrm{~h}$. The brain tissues were cryoprotected by infiltration with $30 \%$ sucrose overnight. Thereafter the tissues were frozen and sectioned with a cryostat at $30 \mu \mathrm{m}$ and consecutive sections were collected in six-well plates 
containing PBS. The sections were sequentially treated with $0.3 \%$ hydrogen peroxide $\left(\mathrm{H}_{2} \mathrm{O}_{2}\right)$ in PBS for $30 \mathrm{~min}$ and $10 \%$ normal horse serum in $0.05 \mathrm{M}$ PBS for $30 \mathrm{~min}$. The sections were next incubated with diluted mouse antiPECAM-1 antibody (diluted 1:1,000; SantaCruz Biotechnology, Calif., USA) overnight at room temperature. Thereafter, the tissues were exposed to biotinylated horse anti-mouse IgG and streptavidin peroxidase complex. The sections were visualized with $3,3^{\prime}$-diaminobenzidine in $0.1 \mathrm{M}$ Tris-buffer and mounted on the gelatin-coated slides.

\section{Western blot analysis}

Five animals in each group were used for immunoblot study. The dentate gyri were dissected from the hippocampus, and homogenized in $50 \mathrm{mM}$ Tris containing $50 \mathrm{mM}$ HEPES (pH 7.4), $0.1 \mathrm{mM}$ EGTA (pH 8.0), 0.2\% NP-40, $10 \mathrm{mM}$ EDTA (pH 8.0), $15 \mathrm{mM}$ sodium pyrophosphate, $100 \mathrm{mM} \beta$-glycerophosphate, $50 \mathrm{mM} \mathrm{NaF}$, $150 \mathrm{mM} \mathrm{NaCl}, 2 \mathrm{mM}$ sodium orthvanadate, $1 \mathrm{mM}$ PMSF and $1 \mathrm{mM}$ DTT. After centrifugation at $10,000 \mathrm{~g}$ for $1 \mathrm{~h}$, the protein concentration was determined in the supernatants by using the Micro BCA protein assay kit with bovine serum albumin as the standard (Pierce Chemical, USA). Aliquots containing $20 \mu \mathrm{g}$ total protein were boiled in loading buffer containing $150 \mathrm{mM}$ Tris ( $\mathrm{pH} 6.8$ ), $3 \mathrm{mM}$ DTT, $6 \%$ SDS, $0.3 \%$ bromophenol blue and $30 \%$ glycerol. Then, each aliquot was loaded onto a $10 \%$ polyacryamide gel. After electrophoresis, the gels were transferred to nitrocellulose transfer membranes. To reduced background staining, the filters were incubated with $5 \%$ non-fat dry milk in PBS containing 0.1\% Tween 20 for 45 min, followed by incubation with mouse anti-PECAM-1 antiserum $(1: 2,000)$ and rabbit anti- $\beta$-actin diluted 1:1,000 (Santa Cruz Biotechnology), with peroxidase conjugated horse anti-mouse IgG (Sigma), and then with ECL kit.

Quantification of data and statistical analysis

In order to quantitatively analyze PECAM-1 immunoreactivity, the corresponding areas of the dentate gyrus were measured from 10 sections per animal. Images of all PECAM-1 immunoreactive structures were taken from 3 layers (molecular, granule cell and polymorphic layers) through an AxioM1 light microscope (Carl Zeiss, Germany) equipped with a digital camera (Axiocam; Carl Zeiss) connected to a PC monitor. Video images were digitized into an array of $512 \times 512$ pixels corresponding to a tissue area of $140 \times 140 \mu \mathrm{m}$ (40x primary magnification). Each pixel resolution was 256 gray levels. The staining intensity of all PECAM-1 immunoreactive structures was evaluated on the basis of a relative optical density (ROD), which was obtained after the transformation of the mean gray level using the formula: ROD $=\log (256 /$ mean gray level). The optical density of background was taken from areas adjacent to the measured area. After the background density was substrated, a ratio of the optical density of image file was calibrated using Adobe Photoshop version 8.0 and then analyzed using NIH Image 1.59 software. The relative percentage of control level was shown in the graph. The result of the Western blot analysis was also scanned, and the ROD was determined using Scion Image software (Scion Corp, USA).

The data shown here represent the means of experiments performed for each experimental area. Differences among the means were statistically analyzed by one-way analysis of variance followed by student Duncan's new multiple range method or Newman-Keuls test in order to elucidate differences among experimental groups.

\section{Results}

\section{Serum level of homocysteine}

Folic acid deficiency rendered the FAD-treated group susceptible to ischemia/reperfusion. After 3 months on the diets, serum levels of homocysteine were determined and found to be 5- to 8-fold higher in gerbils subjected to FAD compared to CD group (Fig. 1).

\section{Change in PECAM-1 immunoreactivity}

In the present study, PECAM-1 immunoreactivity in microvessels in the gerbil dentate gyrus was changed with time after ischemia/reperfusion (Figs. 2, 3). In the CD- and

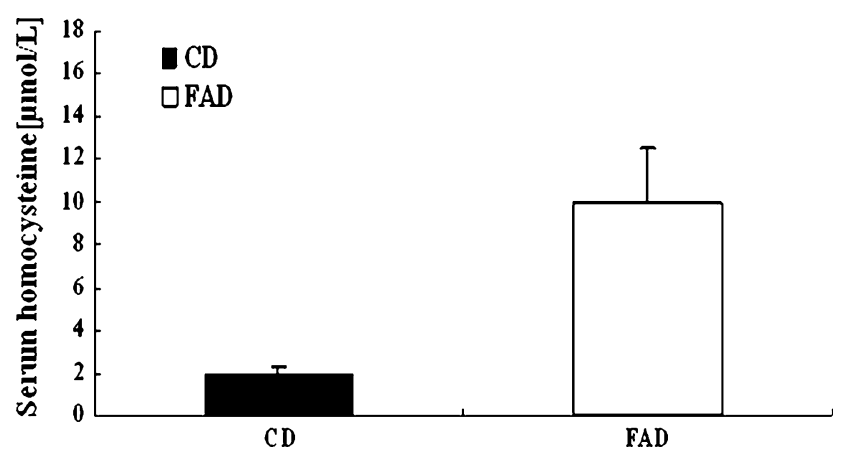

Fig. 1 Gerbils were exposed to a folic acid-deficient diet (FAD) for 3 months and then exposed to transient forebrain ischemia for $5 \mathrm{~min}$. Levels of homocysteine in serum samples of control diet (CD)-treated and FAD-treated animals ( $n=15$ per group). The bars indicate means \pm SEM 
FAD-treated sham-operated groups, weak PECAM-1 immunoreactivity was detected in the blood vessels located in the dentate gyrus (Fig. 2a, b). One day after ischemic insult, PECAM-1 immunoreactivity in the CD-treated group was similar to that in the CD-treated sham-operated group. However, PECAM-1 immunoreactivity in the FAD-treated group was higher by $50 \%$ than that in the CD-treated sham-operated group (Figs. 2c, d, 3). Thereafter, PECAM-1 immunoreactivity in both groups was significantly increased by 4 days after ischemic insult (Figs. 2e-h, 3). At this time after ischemia/reperfusion, PECAM-1 immunoreactivity in the dentate gyrus of the FAD-treated group was much higher than that of the CD-treated group.
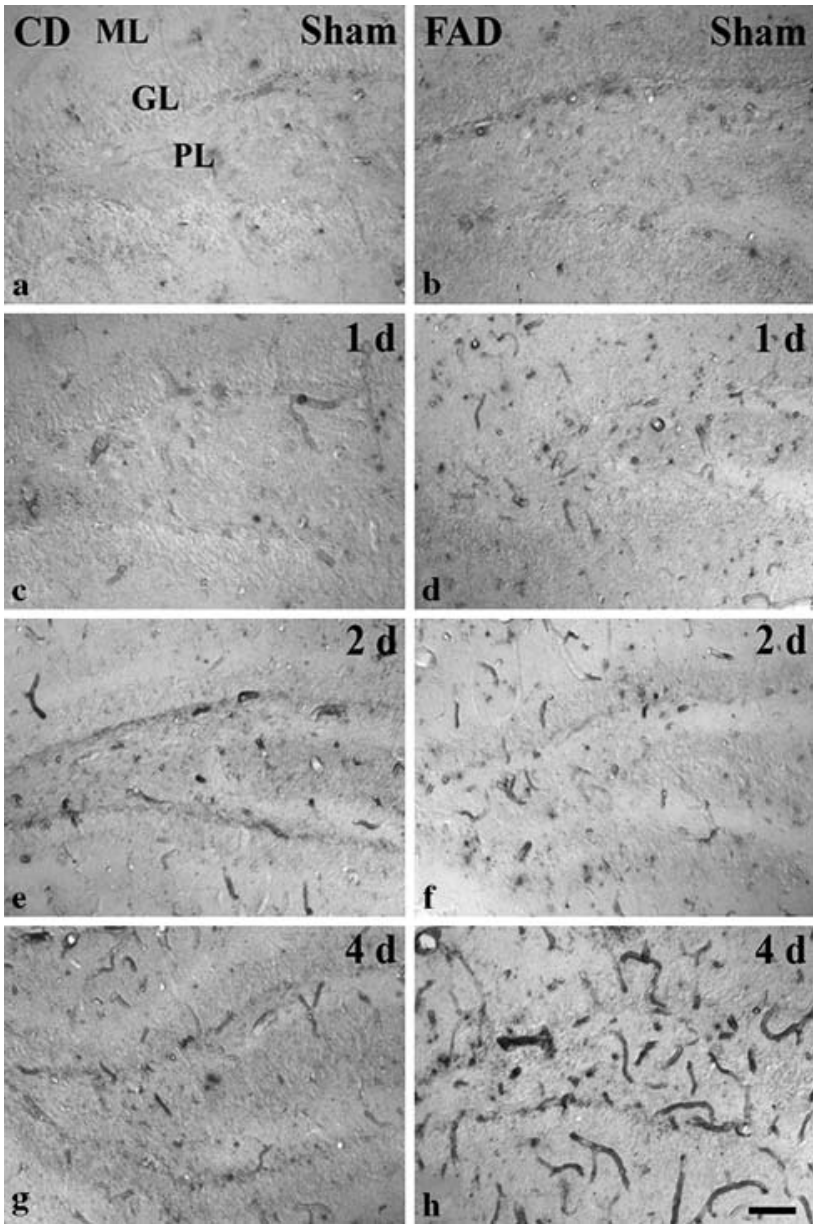

Fig. 2 Immunohistochemistry for PECAM-1 in the dentate gyrus in sham-operated groups (a and $\mathbf{b}$ ) and in ischemia-operated groups at 1 day (c and d), 2 days (e and $\mathbf{f}$ ) and 4 days ( $\mathbf{g}$ and $\mathbf{h}$ ) after ischemia/ reperfusion in CD- and FAD-treated gerbils. In the CD-treated (a) and FAD-treated sham-operated (b) groups, weak PECAM-1 immunoreactivity is detected in microvessels. PECAM-1 immunoreactivity in both groups increases with time. Four days after ischemia/reperfusion, PECAM-1 immunoreactivity in the FAD-treated group (h) is much higher than that in the CD-treated group. $G L$ Granule cell layer; $M L$ molecular layer; $P L$ polymorphic layer. Scale bar $50 \mu \mathrm{m}$

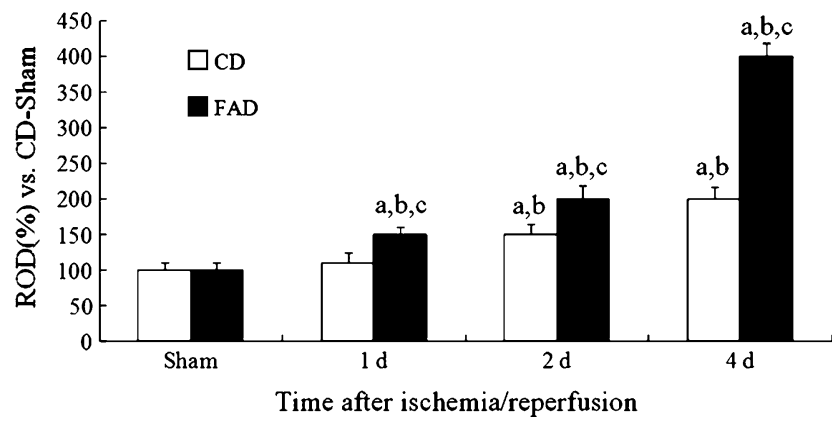

Fig. 3 The relative optical density (ROD) of PECAM-1 immunoreactivity in the gerbil dentate gyrus after $5 \mathrm{~min}$ of transient ischemia. Differences between means were analyzed by one-way analysis of variance followed by Duncan's new multiple range method or the Newman-Keuls test $(n=7$ per group; letter a indicates $P<0.05$, significantly different from the CD- or FAD-treated sham-operated group, respectively; letter $\mathrm{b}$ indicates $P<0.05$, significantly different from the CD- and FAD-treated pre-adjacent group, respectively; letter $\mathrm{c}$ indicates $P<0.05$, between the $\mathrm{CD}$ - and FAD-treated group, respectively). The bars indicate the means $\pm \mathrm{SD}$

\section{Change in PECAM-1 protein level}

In this study, the results of Western blot analyses showed that the patterns of changes in PECAM-1 protein levels in the ischemic dentate gyrus in both groups were similar to changes in PECAM-1 immunohistochemistry in the ischemic dentate gyrus (Fig. 4). One day after ischemia/ reperfusion, PECAM-1 protein level in the FAD-treated group began to increase (Fig. 4). Four days after ischemic

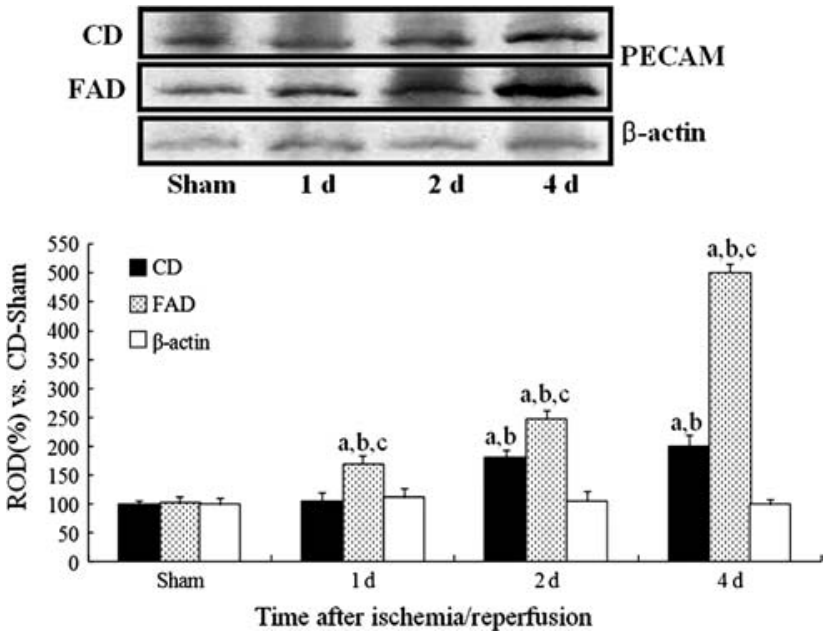

Fig. 4 Western blot analysis of PECAM-1 levels in the gerbil dentate gyrus after ischemic insult. Differences between means were analyzed by one-way analysis of variance followed by Duncan's new multiple range method or the Newman-Keuls test ( $n=5$ per group; letter a indicates $P<0.05$, significantly different from the CD- or FADtreated sham-operated group, respectively; letter $\mathrm{b}$ indicates $P<0.05$, significantly different from the CD- and FAD-treated pre-adjacent group, respectively; letter $\mathrm{c}$ indicates $P<0.05$, between the $\mathrm{CD}$ - and FAD-treated group, respectively). The bars indicate the means $\pm \mathrm{SD}$ 
insult, PECAM-1 protein level in the FAD-treated group was 2.5 times higher than that in the CD-treated group (Fig. 4).

\section{Discussion}

Kirino [17] reported that three different types of ischemic damage were observed in the hilar region of the dentate gyrus, the hippocampal CA1 and CA2 region, after $5 \mathrm{~min}$ of transient forebrain ischemia in gerbils. In the hilar region of the dentate gyrus, neuronal changes were rapid and corresponded to ischemic cell change. Alterations in the $\mathrm{CA} 2$ region were relatively slow and identical to what has been called reactive change; in contrast, changes in the CA1 pyramidal cells were even slower [34].

In the present study, serum levels of homocysteine were found to be 5- to 8-fold higher in gerbils subjected to FAD compared to $\mathrm{CD}$ group. Folate is a cofactor in 1-carbon metabolism, during which it promotes the remethylation of homocysteine. Control of folate has a major impact on homosysteine levels, with an inverse relationship between plasma folate and homocysteins levels [11, 26]. Many epidemiological studies have related folate deficiency and resultant elevated plasma total homocysteine levels with an increased risk of vascular disease and ischemic stroke [8, 11, 12, 19, 26]. Folic acid deficiency and high homocysteine levels can be directly toxic to cultured neurons by mechanisms that involve uracil misincorporation, impaired DNA repair, and DNA damage [20, 21, 23]. Endres et al. [7] reported that folate deficiency in the mouse increased homocysteine level in the serum and cerebral lesion volume.

In the present study, we observed that PECAM-1 immunoreactivity and protein level in the dentate gyrus of the CD- and FAD-treated gerbils were increased with time after ischemic insult. In addition, we found that the immunoreactivity and level of PECAM-1 in the FADtreated group were much higher than those in the CDtreated group after ischemia/reperfusion. Four days after ischemia/reperfusion, PECAM-1 immunoreactivity and protein level in the FAD-treated group was 2 and 2.5 times higher than those in the CD-treated group, respectively. This result suggests that the increase of PECAM-1 immunoreactivity in the microvessels may be associated with the regional susceptibility against ischemic damage after transient forebrain ischemia, and that the elevation of PECAM-1 in the dentate gyrus may be due to neutrophil transmigration [15]. Our data is supported by a report that, in stroke patients, PECAM-1 level was high in serum and cerebrospinal fluid compared to controls [36].

It has been reported that the expression of PECAM- 1 or other cell adhesion molecules were increased in the spinal cord ischemia [4], focal cerebral ischemia [9, 29], and other peripheral ischemia models [31, 33, 34]. The elevation of PECAM-1 immunoreactivity and its protein level in vessels increases the transmigration of lymphocytes and neutrophils [6, 27]. In addition, it was reported that PECAM-1 neutralizing antibody in rats subjected to ischemia/ reperfusion reduced the myocardial infarct [10]. PECAM-1 is expressed on endothelial cells and neutrophils, and has been targeted as a therapeutic route to diminish myocardial infarct size following reperfusion.

It has also been reported that neutrophil transmigration and macromolecular leakage are increased in the ischemia/ reperfusion group, whereas that the increase is attenuated in the animals treated with anti-PECAM-1 antibodies [3234]. In brief, the elevation of PECAM-1 immunoreactivity and protein level in the gerbil ischemic dentate gyrus of the FAD-treated gerbils may be associated with an acceleration of ischemic damage.

Acknowledgments The authors would like to thank Mr. Seok Han, Mr. Seung Uk Lee, and Ms. Hyun Sook Kim for their technical help in this study. This work was supported by the BioFoods Project in Korea biotechnology Research Plan under Ministry of Science and Technology of Korea Government (M10510120004-05N1012-00411).

\section{References}

1. Adibhatla RM, Hatcher JF (2003) Citicoline decreases phospholipase $\mathrm{A}_{2}$ stimulation and hydroxyl radical generation in transient cerebral ischemia. J Neurosci Res 73:308-315

2. Aktas O, Ullrich O, Infante-Duarte C, Nitsch R, Zipp F (2007) Neuronal damage in brain inflammation. Arch Neurol 64:185189

3. Allen JW, Knoblach SM, Faden AI (1999) Combined mechanical trauma and metabolic impairment in vitro induces NMDA receptor-dependent neuronal cell death and caspase-3-dependent apoptosis. FASEB J 13:1875-1882

4. Cassada DC, Tribble CG, Long SM, Laubach VE, Kaza AK, Linden J, Nguyen BN, Rieger JM, Fiser SM, Kron IL, Kern JA (2002) Adenosine A2A analogue ATL-146e reduces systemic tumor necrosing factor-alpha and spinal cord capillary plateletendothelial cell adhesion molecule-1 expression after spinal cord ischemia. J Vasc Surg 35:994-998

5. Clemens JA (2000) Cerebral ischemia: gene activation, neuronal injury, and the protective role of antioxidants. Free Radic Biol Med 28:1526-1531

6. Dangerfield J, Larbi KY, Huang MT, Dewar A, Nourshargh S (2002) PECAM-1 (CD31) homophilic interaction up-regulates $\alpha_{6} \beta_{1}$ on transmigrated neutrophils in vivo and plays a functional role in the ability of $\alpha_{6}$ integrins to mediate leukocyte migration through the perivascular basement membrane. J Exp Med 196:1201-1211

7. Endres M, Ahmadi M, Kruman I, Biniszkiewicz D, Meisel A, Gertz K (2005) Folate deficiency increases postischemic brain injury. Stroke 36:321-325

8. Faraci FM, Lentz SR (2004) Hyperhomocysteinemia, oxidative stress, and cerebral vascular dysfunction. Stroke 35:345-347

9. Ge H, Wen Y, Yang G, Betz AL (2000) Increased expression of intercellular adhesion molecule-1 in mouse focal cerebral ischemia model. Chin Med J 113:75-79 
10. Gumina RJ, el Schultz J, Yao Z, Kenny D, Warltier DC, Newman PJ, Gross GJ (1996) Antibody to platelet/endothelial cell adhesion molecule-1 reduces myocardial infarct size in a rat model of ischemia-reperfusion injury. Circulation 94:3327-3333

11. Hankey GJ, Eikelboom VW (2001) Homocysteine and stroke. Curr Opin Neurol 14:95-102

12. He K, Marchant A, Rimm EB, Rosner BA, Stampfer MJ, Willter WC, Ascherio A (2004) Folate, vitamin $B_{6}$, and $B_{12}$ intakes in relation of risk of stroke among men. Stroke 35:169-174

13. Hossmann K-A (1994) Viability thresholds and the penumbra of focal ischemia. Ann Neurol 36:557-565

14. Hwang IK, Yoo KY, Park JK, Nam YS, Lee IS, Kang JH, Choi SY, Lee JY, Kang TC, Won MH (2004) Ischemia-related changes of adrenocorticotropic hormone immunoreactivity and its protective effect in the gerbil hippocampus after transient forebrain ischemia. Neuroscience 126:871-877

15. Hwang IK, Kim DW, Yoo KY, Jung BK, Song JH, Jung JY, Choi SY, Kang TC, Lee JY, Kwon YG, Won MH (2005a) Ischemiainduced changes of platelet endothelial cell adhesion molecule-1 in the hippocampal CA1 region in gerbils. Brain Res 1048:251257

16. Hwang IK, Eum WS, Yoo KY, Cho JH, Kim DW, Choi SH, Kang TC, Kwon OS, Kang JH, Choi SY, Won MH (2005b) Copper chaperone for $\mathrm{Cu}, \mathrm{Zn}-\mathrm{SOD}$ supplement potentiates the $\mathrm{Cu}, \mathrm{Zn}$-SOD function of neuroprotective effects against ischemic neuronal damage in the gerbil hippocampus. Free Radic Biol Med 39:392-402

17. Kirino T (1982) Delayed neuronal death in the gerbil hippocampus following ischemia. Brain Res 239:57-69

18. Kniesel U, Wolburg H (2000) Tight junctions of the blood-brain barrier. Cell Mol Neurobiol 20:57-76

19. Korczyn AD (2002) Homocysteine, stroke, and dementia. Stroke $33: 2343-2344$

20. Kruman II, Culmsee C, Chan SL, Krumann Y, Gui Z, Penix L, Mattson MP (2000) Homocysteine elicits a DNA damage response in neurons that promotes apoptosis and hypersensitivity to excitotoxicity. J Neurosci 20:6920-6926

21. Kruman II, Kumaravel TS, Lohani A, Pederson WA, Cutler RG, Kruman Y, Haughey N, Lee J, Evans M, Mattson MP (2002) Folic acid deficiency and homocysteine impair DNA repair in hippocampal neurons and sensitize them to amyloid toxicity in experimental models of Alzheimer's disease. J Neurosci 22:1752-1762

22. Lipton P (1999) Ischemic cell death in brain neurons. Physiol Rev 79:1431-1568

23. Lipton SA, Kim WK, Choi YB, Kumar S, D'Emilia DM, Rayadu PV, Arnelle DR, Stamler JS (1997) Neurotoxicity associated with dual actions of homocysteine at the $N$-methyl-D-aspartate receptor. Proc Natl Acad Sci USA 94:5923-5928

24. Lo EH, Moskowitz MA, Jacobs TP (2005) Exciting, radical, suicidal: how brain cells die after stroke. Stroke 36:189-192

25. Lukiw WJ, Bazan NG (2000) Neuroinflammatory signaling upregulation in Alzheimer's disease. Neurochem Res 25:11731184

26. Mattson MP, Shear TB (2003) Folate and homocysteine metabolism in neural plasticity and neurodegenerative disorders. Trends Neurosci 26:137-146

27. Michiels C, Arnould T, Remacle J (1998) Role of PECAM-1 in the adherence of PMN to hypoxic endothelial cells. Cell Adhes Commun 5:367-374

28. Newman PJ (1997) Perspective series: cell adhesion in vascular biology. J Clin Invest 100:S25-S29

29. Okada Y, Copeland BR, Mori E, Tung MM, Thomas WS, del Zoppo GJ (1994) P-selectin and intercellular adhesion molecule-1 expression after focal brain ischemia and reperfusion. Stroke 25:202-211

30. Siesjo BK, Bengtsson F (1989) Calcium fluxes, calcium antagonists, and calcium-related pathology in brain ischemia, hypoglycemia, and spreading depression: a unifying hypothesis. J Cereb Blood Flow Metab 9:127-140

31. Soeki T, Tamura Y, Shinohara H, Sakabe K, Onose Y, Fukuda N (2003) Increased soluble platelet/endothelial cell adhesion molecule- 1 in the early stages of acute coronary syndromes. Int J Cardiol 90:261-268

32. Turegun M, Gudemez E, Newman P, Zins J, Siemionow M (1999) Blockade of platelet endothelial cell adhesion molecule-1 (PECAM-1) protects against ischemia-reperfusion injury in muscle flaps at microcirculatory level. Plast Reconstr Surg 104:1033-1040

33. Wakelin MW, Sanz MJ, Dewar A, Albelda SM, Larkin SW, Boughton-Smith N, Williams TJ, Nourshargh S (1996) An antiplatelet-endothelial cell adhesion molecule-1 antibody inhibits leukocyte extravasation from mesenteric microvessels in vivo by blocking the passage through the basement membrane. J Exp Med 184:229-239

34. Wu B, Iwakiri R, Ootani A, Fujise T, Tsunada S, Fujimoto K (2003) Platelet-activating factor promotes mucosal apoptosis via FasL-mediating caspase- 9 active pathway in rat small intestine after ischemia-reperfusion. FASEB J 17:1156-1158

35. Ying W, Alano CC, Garnier P, Swanson RA (2005) $\mathrm{NAD}^{+}$as a metabolic link between DNA damage and cell death. J Neurosci Res 79:216-223

36. Zaremba J, Losy J (2002) sPECAM-1 in serum and CSF of acute ischaemic stroke patients. Acta Neurol Scand 106:292-298 